\title{
SENTIDO Y FUNCIÓN QUE ELLACURÍA ATRIBUYE A LA FILOSOFÍA
}

\section{THE MEANING AND THE FUNCTION THAT ELLACURÍA ATTRIBUTED TO PHILOSOPHY}

\author{
Pedro Pablo Serna*
}

\section{Resumen}

No sólo el texto "Filosofía, ¿para qué?” nos aporta elementos para poder hacer conciencia del aporte que entrega Ellacuría a una concepción de filosofía. La vocación vital que le permite a este filósofo comprometerse con una realidad que continuamente lo interpela y le dice que su asombro con las cosas no se reduce a las cosas bellas del mundo o de la ciencia, sino que el todo, objeto principal de la preocupación filosófica, con una realidad social bastante cruda, interpela y cuestiona constantemente el quehacer filosófico y lo lleva a ser luz en el horizonte oscuro de la miseria.

\section{Palabras clave}

Vida, filosofía, política, sociedad, el papel del filósofo, la crítica, el cuestionamiento, el pensar.

\section{Abstract}

Not only the text: "Philosophy, what for?" can bring us elements to become aware of the contribution Ellacuría made to a concept of philosophy. The vital vocation that allows the philosophe commit reality that it continually confronts him and tells him that his amazement with things is not limited to the beautiful things of the world or of science. The whole reality is the main object of philosophical concern. Thus, a very crude social reality confronts and questions the philosophical labour and makes the philosopher become a light in the dark horizon of misery.

\section{Keywords}

Life, philosophy, politics, society, the role of the philosopher, criticism, questioning, thinking.

\footnotetext{
* Docente investigador de la Universidad del Norte, Barranquilla.
} 


\section{Sentido de la filosofía}

La vida de Ignacio Ellacuría fue una constante búsqueda de integración de su vida cotidiana y su pensamiento filosófico. Muchos momentos de su vida están marcados por un deseo claro de encontrar la verdad y hacerla pública. Esta fue la causa de su asesinato a manos de los militares salvadoreños.

La realidad interpela al filósofo, lo cuestiona y lo lleva a replantear las posiciones ideológicas de las cuales emana su práctica. Esto lo tenía muy claro Ellacuría, pues lo que más le llamó la atención de su segundo gran maestro, el P. Aurelio Espinoza Pólit, fue la combinación del trabajo intelectual serio y la eficacia pública inmediata (Cardenal, 1989: 1014). No sólo la contemplación es una característica de la filosofía, para Ignacio Ellacuría también lo es la efectividad. A lo largo de su historia personal nos damos cuenta de esto.

¿La filosofía tiene que ser realización de un proyecto social en beneficio de un país concreto? No creo que podamos afirmar esto con facilidad; pero no podemos tampoco negar que la filosofía, o por lo menos el filósofo, tiene una palabra para decir frente a los problemas que aquejan a determinada sociedad y afectar así su contexto. Todo esto tiene que ver con la concepción que tenemos de filosofía; y la filosofía para Ellacuría, más que unos contenidos apilados en la memoria, es una actitud ante la vida. Ver la realidad con ojos de filósofo. La filosofía es el centro del hombre transformador de su realidad. Y es porque el hombre centra su vida en la filosofía por lo que es revolucionario. No por ser revolucionario se es filósofo, pero por qué sí se es filósofo, se es revolucionario.

Para él, la filosofía no la podemos aislar en ningún momento de su carácter político; ya que cualquier cosa que haga el filósofo afecta en sentido positivo o negativo los diferentes procesos sociales que se dan en el mundo.

Estos mismos procesos sociales deben ser iluminados desde la filosofía, pero las diversas corrientes protagonistas de dichos procesos tienden a captar personas que sustentan ideológicamente sus posiciones. Está en el filósofo el no dejarse alienar o manipular por cualquier corriente que limite su capacidad crítica y creativa frente a tales movimientos y realidades.

Sólo quien ame la verdad por la verdad, quien esté dispuesto a darlo todo y esté haciéndolo todo por cargar de realidad las diferentes propuestas ideológicas, puede llamarse filósofo. Filósofo que no será de momento, sino que toda su vida será una manifestación constante de su deseo de clarificación; éste será el aporte verdadero a la liberación por su constante búsqueda de los fundamentos, porque es allá a donde realmente apunta la filosofía.

Por esto, Antonio González, al parafrasear a Zubiri cuando se refiere a Sócrates, dice:

Lo característico de la labor intelectual de Ignacio Ellacuría no consiste tanto en haber puesto la praxis histórica de liberación en el centro de sus reflexiones filosóficas, sino en haber hecho de la filosofía un elemento constitutivo de una existencia dedicada a la liberación (González, 1990: 980).

Tanto a Sócrates como a Ellacuría, situarse desde su ser de filósofo ante la realidad concreta, le trajo consecuencias nefastas contra su vida; por esto para ellos, la filosofía no era un título más sino una actitud ante la vida.

La filosofía de Ignacio Ellacuría es una filosofía política, y por ser política tiene conse- 
cuencias concretas dentro de la vida pública; no porque tenga que aparecer, sino porque la filosofía se convierte en la posibilidad que tiene la humanidad de saberse y de realizarse adecuadamente. El hombre, en la medida que se conoce, se realiza, se hace, se transforma. Allí está el aporte del filósofo a la humanidad. Por esto, es condición del filosofar situarse en la realidad concreta de esta humanidad. Es la única manera como la filosofía puede ser efectiva. En este sentido nos dice:

... la debida politización de la filosofía consistiría radicalmente en hacer del filosofar un pensar efectivo desde la más concreta situación real sobre la realidad más total y concreta. Esta formulación hace hincapié en los siguientes puntos: 1) el pensar filosófico deber ser efectivo; 2) el pensar no puede ser efectivo, si no surge desde una concreta situación real; 3) para que realmente sea efectivo y a la par filosófico, el pensar filosófico tiene que estar anclado en la realidad total que, como total, es concreta (Ellacuría, 1972: 53- 54).

Este situarse en la realidad exige un esfuerzo académico, disciplina y responsabilidad. Si la filosofía es la instancia suprema de la racionalidad, debe configurar el mundo al que la filosofía responde y debe dirigir; este mundo que obliga a la filosofía a ser más histórica y política porque él en su última determinación será más histórico y más político. Esta labor es de la filosofía, por eso Ellacuría ve en la universidad un espacio privilegiado para pensar lo político; pero para esto es necesario reconocerse afectados por la misma realidad; reconocerse como realidad psicobiológica, un ser biosocial que tiene intereses que pueden determinar lo que captamos y sobre lo que nos atrevemos a racionalizar. Toda la realidad nos toca, nos limita y posibilita. Si racionalizamos aún nuestros intereses y necesidades, y el modo como estas afectan nuestro conocimiento, podemos hacer que el pensamiento surja, podemos crear, interpretar de un modo más universal las realidades con las que tenemos contacto. Debemos reconocer los condicionamientos que ellas pueden ejercer en el pensar mismo y de esta manera podremos liberarnos de lo que pueda impedir un mejor acercamiento a la verdad. Estos impedimentos pueden ser sociales, personales, políticos, etc. (1976: 75).

Estos condicionamientos pueden limitar la autonomía de la filosofía y por eso es necesaria una visión crítica y libre para poder dar pasos en la búsqueda de racionalidad que realmente beneficie a la humanidad. Es desde esta concepción expresada en el texto de Ignacio Ellacuría "Filosofía, ¿para qué?", donde se comienza a perfilar su visión sobre la función que le corresponde a la filosofía.

El saber filosófico es así un ingente esfuerzo de la humanidad por aclararse a sí misma qué es saber, qué es realidad y cuál es el sentido de la vida humana. Es un esfuerzo estrictamente racional, un esfuerzo sin el que a la postre le faltaría a la humanidad racionalidad y criticidad (1976: 73).

La visión que de la filosofía tiene Ignacio Ellacuría en el texto "Filosofía, ¿para qué?" es completada en el texto "Función liberadora de la filosofía"; en este último profundiza en el carácter dinamizador de la realidad que tiene la filosofía verdadera, que se piensa a sí misma, y en este camino concibe la sociedad con sus características, situaciones, problemas, necesidades, vacíos de verdad, etc.

El papel que desempeña el filósofo es el de filosofar. Fueron las circunstancias, su sacerdocio, su rectoría de la UCA, lo que llevó a Ellacuría a tener más presencia pública; pero 
no podemos negar que el fundamento de su trabajo intelectual y crítico está en la misma filosofía que lo llevaba constantemente a buscar lo realmente racional de las diferentes situaciones del Salvador; por lo apela al dato y así situar la función que como filósofo le corresponde. Esto requiere de una visión de la filosofía como un modo de vida, que después de asumido, no puede dejar de mirar la realidad desde ésta.

La mirada filosófica, situada en la realidad, tendría una capacidad liberadora desde las posibilidades que tiene de ser crítica y creadora a la vez.

Evidentemente estos son dos poderosos factores de liberación y no sólo de liberación interior o subjetiva sino también, aunque en un grado reducido y complementario, de liberación objetiva y estructural (1985: 47).

Por este motivo, “en la mente de Ellacuría, liberación y filosofía se hallan en inmediata y directa respectividad. La filosofía en su esencia contiene una dimensión liberadora" (Domínguez, 1993: 43). Estos dos factores de los que nos habla Ellacuría son parte fundamental de su propuesta filosófica; son características de la misma filosofía en su proceder teórico, en ellas se fundamenta el aporte que la filosofía otorga.

Las propuestas filosóficas son siempre propuestas teóricas, son teoría, por lo tanto, es desde la teoría desde la que va a cumplir realmente su función. Este es el campo que le corresponde.

Pero, ¿por qué puede ser importante el campo de lo teórico en medio de una realidad que agrede, que limita, que oprime, que esclaviza a la persona humana?, ¿puede realmente la filosofía aportar algo en la solución de este tipo de conflictos? La filosofía debe ir al fundamento mismo de las situaciones, reforzadas con argumentos ideológicos, los cuales pueden estar totalmente vacíos de realidad. Apelar al fundamento nos lleva a descubrir lo que de verdad tienen estas situaciones; $y$ el descubrimiento de las falacias es ya un paso necesario en los procesos de transformación social; porque "Ideología siempre la va a haber en su sentido negativo; por ello son necesarias las instancias teóricas que la combatan desenmascarándola e iluminándola" (Ellacuria, 1985: 47).

Ya veníamos hablando de las dos funciones concretas que tiene la filosofía para hacer frente a la realidad tal como se nos presenta: una función crítica y una función creativa; las dos están íntimamente ligadas en el mismo aporte filosófico que se hace a las situaciones reales para transformarlas.

\section{Funciones de la filosofía}

El carácter iluminador que tiene la filosofía cumple su función cuando la misma teoría ha servido o se ha utilizado para beneficio de una clase, ideología, corriente determinada, sin tener en cuenta la realidad, en detrimento de la verdad completa. Por esto podemos afirmar, con Ellacuría, que es frente a este tipo de ideología donde se define en buena medida la función crítica de la filosofía (1985: 47).

\section{Función crítica}

Es función de la filosofía de cuestionar, revalorar, replantear las posiciones de la ideología dominante primordialmente, como manifestación más clara de un sistema social. También, de manera lógica apuntará a todas aquellas situaciones y elementos de la misma estructura social que pueden y deben ser cuestionadas (1985: 47).

Esta función crítica de la filosofía nos hace ver a la misma filosofía como fundamen- 
talmente política, pues su tarea también es política; puede tener incidencias sociales claras. Por esto el filósofo desempeña una función pública.

El filósofo no piensa ni habla para sí sólo ni desde sí sólo, del filósofo no puede esperarse que trate de resolver para sí mismo los problemas que aborda sino que ofrezca a la colectividad humana una crítica y una interpretación de la realidad que puedan iluminar desde su raíz última la relación de todo hombre con el mundo (Domínguez, 1993: 44).

La función del filósofo se realiza desde la crítica de la realidad; desde el indagar permanentemente sobre las deficiencias que tienen las sociedades; y ha de ponerse del lado de la verdad que puede forjar procesos que generen plenitud al hombre y a sus comunidades.

Este indagar no puede calificar lo ideológico como negativo por sí mismo. Todas las sociedades poseen un conjunto de ideas que las orientan, lo que le corresponde al filósofo es ver qué tanta realidad tienen estas ideologías; cuánto engaño hay en ellas; cuál es realmente su fundamento y cuáles son las consecuencias que estas puedan tener para el conjunto de la sociedad.

En el cuestionamiento de los intereses reales que motivan determinada ideología, también caben los intereses ideológicos del mismo pensador, del filósofo: ¿a dónde apunta?, ¿qué buscan?, ¿qué intereses personales existen? La función crítica de la filosofía también es necesario ejercerla con relación al crítico, al filósofo.

Esto posibilita que el resultado último del quehacer filosófico esté lo suficientemente cargado de realidad y que aquello buscado lleve a concretar un compromiso con la realización plena de lo humano. Lo filosófico es un compromiso con la humanidad y todo aquello que lo circunda; en su carácter creativo, la filosofía es liberadora y además política.

\section{Función liberadora}

La liberación real de los pueblos, la búsqueda de la realización plena de lo humano, no la podemos lograr sólo por la vía negativa, diciendo que tal o cual cosa o situación no tiene validez porque sus fundamentos no poseen la más mínima señal de realidad. Se hace necesario tener iniciativas, capacidad de diseño, creatividad, porque...

... el camino debe proseguirse hacia formas más creativas que no sólo digan lo que de ideologizado hay en un determinado discurso, sino que logren un nuevo discurso teórico que en vez de encubrir y/o deformar la realidad la descubra, tanto en lo que tiene de negativo como en lo que tiene de positivo (Ellacuria, 1985: 52).

La función liberadora de la filosofía es completa cuando se da un paso posterior a la crítica; cuando vamos de la desfundamentación real de las ideologías a sugerir posibles caminos de solución real a los problemas que aquejan a la humanidad.

\section{Función política}

El filósofo ha revisado su propio conjunto de ideas, lo ha replanteado, lo ha fundamentado. En este proceso ha llegado a cuestionar los planteamientos que desde una ideología dominante se hacen. Va a sus fundamentos, a lo que de realidad tiene; y es desde estos que va a construir un discurso que exprese lo que realmente está cargado de realidad. Es la sugerencia de un nuevo horizonte en el que se busca la plenitud de la comunidad humana. 
Así es como aparecen nuevos planteamientos teóricos que se ofrecen como alternativas de solución a los problemas históricos. Es la creatividad del filósofo al servicio de la verdad; no como el que va a generar, determinar, dirigir los procesos liberadores. Porque los filósofos, y sobre todo hoy en día, no se pueden considerar como los que manejan y lo transforman todo, pues "sería ingenuo pensar que las grandes realizaciones sociales y aún los comportamientos personales dependen últimamente de formulaciones filosóficas" (Ellacuría, 1985: 53); pero no podemos tampoco negar que es fundamental el aporte que la filosofía puede hacer a los procesos históricos desde el uso de la racionalidad.

Este aporte correspondiente a la filosofía nos lo aclara Ellacuría diciéndonos lo siguiente:

... La filosofía debe desempeñar siempre una función liberadora, pero el modo de desempeñarla es distinto y esto va a hacer que haya filosofías distintas con su propia universalidad. No hay una función liberadora abstracta y ahistórica de la filosofía; hay, por tanto, que determinar previamente el qué de la liberación, el modo de la liberación y el adónde de la liberación; el paso del previamente al definitivamente, el paso de la anticipación a la com-probación dará por resultado una filosofía original y liberadora, si es que realmente se ha puesto en el lugar adecuado del proceso liberador (1985: 55).

Los procesos a los que debe hacer alusión la filosofía son históricos y por lo tanto deben tener su fundamento en la realidad; por eso, para que la filosofía sea realmente liberadora debe ser una filosofía situada y desde esta situación cumplir su función. La filosofía se puede presentar como una luz que ilumina el camino para ver dónde se pisa; la luz que ilumina la realidad, la interpreta para transformarla. Es el uso de la inteligencia humana lo que puede llevarnos a descubrir nuevos caminos más racionales y más humanos para una sana convivencia: más ética, más justa, más plena.

La función liberadora de la filosofía parte de estos principios, pero va dirigida también al mismo filósofo, quien es capaz de descubrir nuevos horizontes para su vida, llegándose a dar un proceso subjetivo de libertad interior, de replanteamiento interior que lo lleve a poner su vida al servicio de la verdad.

La transformación real de la situación social le corresponde a los sujetos mismos de la realidad, a quienes sufren directamente las consecuencias de la realidad degradante y opresora. El filósofo aparece, en esencia, en el momento teórico de la praxis histórica. No desaparece necesariamente de las acciones concretas que llevan a construir un nuevo sistema; pero su función primordial es aportar desde el campo de la racionalidad nuevos fundamentos a una nueva sociedad. Fundamentos anclados en la realidad, en las situaciones reales. Esto sólo lo logrará si mira la realidad desde una distancia prudente que le posibilite la plena autonomía de los procesos sociales que se están dando, porque la filosofía sigue siendo una tarea en la que predomina lo teórico; y de esta manera, evitar ser un admirador y embelesado funcionario de determinada praxis social que podría limitar su capacidad crítica.

El único modo como la filosofía se convierte en lo que debe ser es cuando se pone a disposición de la búsqueda de la verdad que realmente libera. Ese es para Ellacuría el lugar privilegiado desde donde podemos llegar a la función de la filosofía y será el lugar privilegiado de la praxis verdadera (1985: 62). 
Lugar, porque la praxis eficaz de liberación exige y requiere lo teórico como aporte al proceso total, eso sí autónoma, frente a la misma praxis liberadora.

La filosofía hace parte de la praxis total, de la praxis histórica; pero no se puede diluir en las acciones limitadas que se ocupan de la transformación. No por esto podemos oponerla a la praxis sino que debemos entenderla como un momento privilegiado de ella (1985: 63).

\section{Características y bases de la filosofía de Ellacuría}

Son diferentes las corrientes filosóficas con las que Ellacuría tuvo profundo contacto, en las que algunas marcarían más su quehacer filosófico que otras ${ }^{1}$. Es indiscutible la estrecha relación entre los planteamientos de Ellacuría con la filosofía de Zubiri, la identificación con sus concepciones principales. Por esta razón, encontramos algunas de las características de la filosofía de Zubiri.

El que Zubiri planteara una discusión con la tradición filosófica llevó también a Ellacuría a conocer, en gran medida, la historia de la filosofía y a discutir con ésta. Por eso mismo, no podemos afirmar que el jesuita siga ciegamente los planteamientos de Zubiri, sino que asumiendo críticamente sus teorías exponen

1 Ignacio Ellacuría realizó sus primeros estudios filosóficos en Ecuador; pero esta filosofía, de corte neoescolástico, no le llamará tanto la atención. Se centró más en la filosofía de Ortega y Gasset y de Bergson, antes de viajar a Insbruck a estudiar la teología, donde se encontraría con Karl Rahner y, por medio de él, con la filosofía de Heidegger y el existencialismo, corrientes que posibilitaron el diálogo fecundo con Xavier Zubiri, su último gran maestro, que lo marcaría definitivamente a él y su filosofía. Con él hizo su tesis doctoral "La principialidad de la esencia en Xavier Zubiri”. Desde este tiempo, el pensamiento ellacuriano siempre tendrá en cuenta los principios básicos aprendidos con Zubiri. elementos nuevos desde su misma experiencia y desde lo que se podría considerar como su historia y proceso filosófico.

Son muchos los elementos de la filosofía zubiriana que influyen de modo positivo en el pensamiento de Ellacuría; elementos que son replanteados, repensados, revalorados desde la misma situación histórica de quien los interpreta y de la realidad que los afecta. Es así como Ellacuría asimila profundamente la metafísica de Zubiri, insistiendo en los dos elementos que más encontramos en su filosofía: la teoría de la inteligencia y la teoría de la realidad. El concepto de realidad lo estudiaremos profundamente en el segundo capítulo de este trabajo; sin embargo quisiera presentar aquí algunos elementos necesarios.

\section{Nueva concepción del conocimiento}

La "inteligencia sentiente" fue un tema profundizado por Zubiri y retomado por Ellacuría. El tema de la inteligencia, la manera de acceder a la realidad, la posibilidad que tiene el hombre de acceder a esa realidad, lo que nos es dado a conocer, el cómo la realidad nos toca, la diferenciación entre el ser y el conocer, la relación que hay entre lo que es y lo conocido, son temas que fueron abordados por muchos filósofos en el transcurrir de los siglos. Zubiri no puede ser la excepción, porque se hace necesario, para poder hablar de realidad, ver la manera como el hombre accede a ella.

En su planteamiento sobre la inteligencia, Zubiri supera, según Ellacuría, el reduccionismo que el idealismo hace de la inteligencia. La filosofía en toda su historia ha venido manifestando la diferenciación clara entre sentir e inteligir. Zubiri, con la integración, pretende acusar al idealismo de haber incurrido en una logificación de la inteligencia. Se presenta a la inteligencia como capacidad para captar algo que está más allá de lo que experimentamos, 
de lo que sentimos; que está más allá de la misma realidad, por ende, no es sólo en la aprehensión como captamos la realidad sino que "la intelección es primariamente logificación y que ha de llegarse a esa actualización secundaria para que la intelección se encuentre con la realidad" (Ellacuría, 1988: 636); también se acusa al idealismo de haber incurrido en una entificación de la inteligencia, se entiende a la realidad sólo como un modo del ser que, a su vez, sería separado de la cosa misma; de la realidad; porque el ser sería un algo muy superior a las cosas. La realidad como tal no podría mostrar realmente lo que es el ser (1988: 633-650).

El planteamiento zubiriano de la inteligencia busca cortar con esta visión, planteando la inteligencia sentiente como una manera de acercarnos a la realidad desde la capacidad que tiene el hombre de inteligir y sentir al mismo tiempo. Es una concepción unitaria de la realidad. No hay dualidad en el acto del conocer ni en la realidad misma. La realidad es una misma y como tal se nos manifiesta, porque la realidad siempre es. Es a captar la realidad a lo que se dedica la inteligencia. El sentir e inteligir son dos vías de captación del carácter de realidad que tienen las cosas.

La inteligencia humana es fundamentalmente una actividad biológica que facilita el acceso a lo real en cuanto tal. Con esto no se quiere decir que el conocer intelectivo no se diferencie de la actividad puramente sensorial o de la mera actividad vegetativa. Lo que se afirma es que en ninguno de los ejercicios de la inteligencia, por muy elevado que sea, dejan de operar el carácter biológico y sensorial que es constitutivo del ser humano ni la esencial orientación de toda actividad humana al sostenimiento de la vida (Domínguez, 1989: 82).

\section{Nueva concepción de realidad}

Partiendo de su concepto de inteligencia sentiente, mencionado con anterioridad, podemos llegar con más facilidad a su concepto de realidad; el nuevo realismo sugerido por Zubiri. Realidad totalmente dinámica, que de manera continua está dando más de sí, ofreciendo posibilidades que puedan ser desarrolladas, tanto por la naturaleza, como por la historia; mejorando o empeorando las condiciones en que son asumidas. El ser humano se encarga de la realidad y la transforma; no sólo la contempla.

Los conceptos de inteligencia sentiente y realidad están relacionados, ya que no puede darse el saber sin realidad y no puede haber realidad sin saber. Hay una relación ínsita, natural en estos dos aspectos del ser humano que grandes filósofos reconocidos en la historia de la filosofía han visto separadas. Las cosas reales se actualizan en el hombre mediante la inteligencia sentiente. Es en ese contacto con las cosas como percibimos y conocemos realmente la realidad. Los sentidos, que nos posibilitan el acercamiento a las cosas, son el único acceso a la realidad misma; y es la inteligencia la que permite el reconocimiento de tales cosas como realidad. Ya la realidad no es el mero estímulo, sino todo aquello que la inteligencia me permite saber de lo que me toca, y también de aquello que no me toca, pero que es posible que haga parte de mi universo.

Si la realidad tiene una estructura, yo puedo, mediante la inteligencia, tener acceso a ella, igual que con todas sus características propias. Los animales no se hacen cargo de la realidad, sólo reaccionan con los estímulos.

La realidad está intrínsecamente diferenciada en posibilidades infinitas de cosas reales; y a pesar de esto es una misma realidad (Domínguez, 1989: 85). 
A mi modo de ver, es enraizado en estos elementos como Ellacuría llega a plantear la necesidad constante de fundamentarse en la realidad. Su trabajo y producción filosófica siempre será fiel a la realidad que se le está presentando con datos y con la que él tiene contacto constantemente. Quiere evitar las construcciones teórico-especulativas que lo podrían alejar de la realidad como tal. En esto se prueba su interés científico por los datos.

\section{Dinamicidad y poder de la realidad}

A lo anterior se añade la explicitación de un aspecto de la realidad: la dinamicidad y poder de lo real; que es la capacidad que tiene la realidad para ir dando cada vez más de sí.

El ser real está constituido por un conjunto de notas que permanece abierto a transformaciones e incrementos (Domínguez, 1989: 86). Con esto vemos que la realidad no es estática, porque la realidad es una fuerza determinadora que subyace en las posibilidades, sustentándolas y concretándolas (1989: 86). La realidad no es lo ya hecho. La realidad se está haciendo y se hace más en la medida en que el hombre aporta a ella, con su inteligencia, recreando las mismas posibilidades que la realidad le ofrece.

\section{Referencias}

Acevedo, C. (1993). El legado filosófico-político de Ignacio Ellacuría. ECA, 541-542.

Cardenal, R. (1989). Ser jesuita hoy en El Salvador. ECA, 493-494, 1013-1021.

Conill, J. (1988). Por la fenomenología a la metafísica. En El crepúsculo de la metafísica. Barcelona: Anthropos Editorial.

Domínguez, M. (1989). Ignacio Ellacuría, filósofo de la realidad latinoamericana. Universitas philosophica, núm. 13. Bogotá: Pontificia Universidad Javeriana.
Domínguez, M. (1993). Aproximaciones al concepto de praxis en Ignacio Ellacuría [conferencia]. Bogotá: Pontificia Universidad Javeriana.

Ellacuría, I. (1972). Filosofía y política. ECA, núm. 284.

Ellacuría, I. (1975). Hacia una fundamentación del método teológico latinoamericano. ECA, 322-323, 409-425.

Ellacuría, I. (1976). La historización del concepto de propiedad como principio de desideologización. ECA, 335-336, 425-449.

Ellacuría, I. (1976). Filosofía, ¿para qué? $A B R A$, núm. 2, 42-48.

Ellacuría, I. (1979). El concepto filosófico de tecnología apropiada. ECA, núm. 366, 213-223.

Ellacuría, I. (1979). Fundamentación biológica de la ética. ECA, núm. 368, 419-428.

Ellacuría, I. (1980). Universidad y política. $E C A$, núm. 383, 807-824.

Ellacuría, I. (1981). La nueva obra de Zubiri: inteligencia sentiente. Razón y fe, núm. 995, 126-139.

Ellacuría, I. (1985). Función liberadora de la filosofía. ECA, núms. 435-436, 45-64.

Ellacuría, I. (1990). Filosofía de la realidad histórica. San Salvador: UCA Editores.

Ellacuría, I. (1991). Escritos políticos. Veinte años de historia en El Salvador. 19691989. San Salvador: UCA Editores.

Ellacuría, I. (1998). Superación del reduccionismo idealista en Zubiri. ECA, núm. 477: 633-650.

González, A. (1987). El hombre en el horizonte de la praxis. ECA, núms. 459-460, 57-87. 
González, A. (1990). Aproximación a la obra filosófica de Ignacio Ellacuría. ECA.

Gracia, D. (1986). Voluntad de verdad. Barcelona: Editorial Labor.
Zubiri, X. (1989). Estructura dinámica de la realidad. Madrid: Alianza Editorial.

Zubiri, X. (1986). Sobre el hombre. Madrid: Alianza Editorial. 